100 Literatura e Sociedade

\title{
REALISMO E PERDA DA REALIDADE: O NATURALISMO DE ZOLA
}

\author{
Salete de Almeida Cara
}

Universidade de São Paulo

\section{Resumo}

O romance Au bonheur des dames, de Émile Zola, confere ao próprio consumo a centralidade que passará a ter em relação ao sistema de produção no mundo contemporâneo. O presente ensaio pretende examinar de que modo a mercantilização da vida está configurada na forma desse romance, no âmbito do legado realista que o escritor deixa aos prosadores que o sucederam.

\section{Abstract}

Émile Zola's novel Au bonheur des dames gives to consumption itself the central role it would take vis-à-vis the system of production in the contemporary world. Our purpose is to examine in which way this novel renders life's merchandization, viewed in the context of the realistic legacy the author hands down to subsequent prose writers.
Palavras-chave

Prosa realista; mercantilização; encenação épica; enredo romanesco.

Keywords Realistic prose; merchandization; epic dramatization; novelistic plot. 
prosa de Émile Zola desafia o leitor e pode mesmo enganá-lo, pelo modo como apanha sua matéria no exato momento em que ela tomava novas configurações e, portanto, exigia novas formas narrativas. Em cada um dos romances e no conjunto que eles armam, o tempo da narrativa e o dos anos em que o escritor trabalhou na sua construção têm, ambos, presença decisiva na exposição desafiadora do processo de mercantilização da vida ditado pelo capital, que começara a se internacionalizar sob Napoleão III. Em Au bonheur des dames (1883), que vou aqui examinar, o processo é exposto de modo particularmente curioso pela forma do romance, desafiando o leitor de hoje, que vive em grau extremo a mercantilização dos seus próprios desejos. ${ }^{1}$

Nos romances do ciclo dos Rougon-Macquart, Zola mostrou que suspeitava das promessas de autonomia do sujeito nos termos do desenvolvimento de um processo histórico, de ordem política, desconfiando também que os melhoramentos da vida moderna não iriam poupar meios de evitar que a fatia da vida mais espoliada perturbasse a sua marcha. O que, de certo modo, estava nos romances de Balzac. Mas, não à toa, Zola chamava fantasmagoria ao excesso de imaginação balzaquiana, que o irritava. O enredo amoroso (na falta de termo melhor) de $A u$ bonheur des dames sinaliza bem a distância que ele toma de enredos que ainda pressupunham a existência de uma liberdade humana massacrada pelos interesses da máquina burguesa.

${ }^{1}$ O ciclo dos Rougon-Macquart se passa entre 1850 e 1874 e traz a experiência do II Império de Napoleão III (1852-1870). Concebido nos fins dos anos de 1860, foi escrito e publicado entre 1871 e 1893, durante a III República, inicialmente capitaneada por Thiers, o responsável pelo massacre da Comuna de Paris em 1871. Trata-se da República de uma burguesia "hoje enlouquecida com as revoluções que vêm de baixo", escreve Lissagaray no prefácio à segunda edição do seu livro, em 1896, referindo-se ao acirramento das lutas dos trabalhadores por seus direitos (ver Prosper-Olivier Lissagaray, História da Comuna de 1871, Trad. Sieni Maria Campos, São Paulo, Ensaio, 1991). 
O passo dado pelo romance de Zola elimina essa dualidade, e é bem maior do que leva a pensar a referência que faz Theodor Adorno ao romance naturalista, ao comentar a avaliação de Engels, que prefere Balzac a "todos os Zolas passados, presentes ou futuros". Embora Adorno se refira àqueles momentos nos quais se daria uma "representação dos fatos sob a forma de protocolo", creio que a prosa de Zola vai mais longe, como mostra Au bonheur des dames, romance que dá ao próprio consumo a centralidade que passará a ter em relação ao sistema de produção industrial no mundo contemporâneo, mostrando o início de um consumo de massa (implicando rapidez na substituição dos estoques e novos modos de exposição das mercadorias), justificado por uma pretensa democratização do comércio de luxo. ${ }^{2}$

Centralidade que desestabiliza, pela mediação das mercadorias, o caráter essencialista de valores que sustentavam o projeto burguês de harmonia social (os bons propósitos morais do indivíduo, a dependência entre mérito e sucesso, a manutenção das diferenças de classe social, entre outros), em relação aos quais o romance naturalista de Zola estabelecia uma distância crítica, na medida mesma em que punha sob suspeita o modelo de trama romanesca que os valorizava, escamoteando justamente a complexidade de um sistema econômico que tinha interesse nessas encenações maniqueístas, ainda que, nelas, os seus próprios agentes aparecessem como vilões. Em Au bonheur des dames não há vilões no sentido romanesco. O que se passa?

Nos anos de 1880, Zola escreveu romances como Nana (1880), Pot-Bouille (1882), Au bonheur des dames (1883), Germinal (1885) e La Terre (1887). No mínimo, essas obras dão a ver que não é de natureza simples a presença constitutiva da experiência na forma de romances que não tinham no seu horizonte a imediatez da empiria, apreendendo seus objetos enquanto processo, isto é, enquanto transformação e permanência de estruturas sociais, onde aos destinos humanos não caberiam previsões nem leis inevitáveis (como, de resto, Zola expôs nos seus textos críticos) ${ }^{3}$

\footnotetext{
2 "Quando ele prefere Balzac a 'todos os Zola passados, presentes ou futuros', ele não quis fazer alusão senão àqueles momentos nos quais o primeiro é menos realista do que seu sucessor cientista, que não substituiu por acaso o conceito de realismo pelo de naturalismo. [...] Mas quando o naturalismo dedicou-se à representação dos fatos sob a forma de protocolo, o dialético também se alinhou ao lado do que os naturalistas baniam como metafísica, rebelando-se contra a educação automática do gênero humano. De fato, a própria verdade histórica não é nada mais do que esta metafísica que aparece e se renova pela demolição permanente do realismo. É justamente a fidelidade de fachada de um procedimento purificado das deformações balzaquianas que pactua, na indústria cultural como no realismo socialista, com as intenções introduzidas de fora, que não conseguem nem por um segundo reverter a narrativa balzaquiana: o protocolo se justifica em relação a acontecimentos corroídos, mas, em literatura, todo planejamento representa a tendência dominante. [...] Para ele [Engels] a grandeza de Balzac se revela justamente nas apresentações que se opõem às suas próprias simpatias de classe e de seus preconceitos políticos, e que desacreditam a tendência legitimista" (ver Theodor Adorno, "Lecture de Balzac", in Notes sur la littérature, 5.ed. Paris, Flammarion, 1984, p. 95).

${ }^{3}$ Nesse momento a ideologia liberal-republicana de progresso e coesão social procurava desqualificar os conflitos entre classes sociais, que resultavam da organização dos trabalhadores, enquanto recuperava o impulso industrial, inaugurado pelo II Império com a construção de ferrovias e fabricação de trilhos de aço, seriamente abalado com as perdas financeiras trazidas pela guerra franco-prussiana.
} 
Pode parecer estranho dizer que Au bonheur des dames traz uma contribuição particular a essas relações ao embutir num desfecho aparentemente feliz o fracasso do indivíduo, pondo em evidência o caráter corrosivo das relações mercantis que o colonizam, ainda que se chame integridade à sua subordinação cordata aos desígnios do capital. É assim, no entanto, que Au bonheur des dames compõe o quadro pressuposto pela prosa de Zola como etapa final do romance realista. Resta saber de que modo ele o faz. Se o romance de Zola depende do espaço das grandes lojas, que sua prosa chama "novos templos", as relações que ali se dão são expostas pela convivência tensa entre aquilo que revela a épica de um horror domesticado, e aquilo que pretende ocultar uma intriga melodramática.

A matéria de vasto assunto dos seus romances exigia encenação epicizante, e o escritor encontrou na prosa de Flaubert um aliado: não se interessar pelo romanesco, pela "invenção extraordinária", pela intriga ainda que a mais simples (o que dizer das rocambolescas e surpreendentes?), pela construção de heróis, pela presença excessiva do autor impedindo as conclusões do próprio leitor. Tais resoluções de conteúdo e forma, às quais Zola deu desdobramentos, não dependeram do abandono do otimismo quanto ao futuro ou de uma perspectiva revolucionária do próprio escritor. Ao discorrer sobre suas expectativas, Flaubert sacudia os ombros ("quando eu afirmava minhas crenças no século XX, quando eu dizia que nosso vasto movimento científico e social devia resultar numa plenitude de humanidade..."). ${ }^{4}$

Ainda que Zola apostasse no projeto de harmonia social com lugar para as ditas virtudes filantrópicas, no qual se empenhava o liberalismo conservador da III República, é complexa a tensão formal que atravessa Au bonheur des dames. O romance se passa entre 1864 e 1869, e mostra a vida num grande magazine com estoques a preço baixo e enorme variedade de mercadorias, do tipo daqueles que encontraram seu espaço na Paris do II Império, transformada pelo prefeito imperial Haussmann, e cuja reforma se tornou símbolo de modernidade urbana de alcance internacional (não só pelas técnicas de engenharia empregadas na reconstrução da cidade, mas também porque a reforma retirou os pobres do centro da cidade). As grandes lojas de departamento ganharam impulso durante a III República.

Walter Benjamin viu esse tipo de loja como herdeira das antigas passagens parisienses - galerias cobertas que serviam ao luxo industrial, desde o início do século

\footnotetext{
${ }^{4}$ No caso da Comuna de Paris que, como escreveu Prosper-Olivier Lissagaray, em 1876, foi um movimento da classe trabalhadora, patriotas republicanos massacrados, banidos e renegados por republicanos, e que Émile Zola tratou em La débâcle (1892), o resultado foi o fracasso do narrador e a configuração de uma crise da forma do romance. Em Marx, Zola e a prosa realista, procurei mostrar as condições objetivas das dificuldades de Zola (ver Salete de Almeida Cara, Marx, Zola e a prosa realista, São Paulo, Ateliê Editorial, 2009). Enquanto La débâcle configura a Comuna de Paris como um impasse formal que o escritor não supera, os demais romances do ciclo mostram o alcance crítico de sua prosa numa faixa de temporalidade mais ampla do que a do II Império. Cabe lembrar que trinta anos antes, no romance de Flaubert A educação sentimental (1862), os massacres de 1848 estavam presentes pelo viés de um jovem burguês afeito às musas, cuja posição indiferente e centrada em aventuras pessoais o escritor mostrou com ironia, segundo a leitura de Dolf Oehler.
} 
XIX. "As passagens como templo do capital mercantil", escreve Benjamin no seu estudo sobre o papel da forma mercadoria na vida dos homens. "Pela primeira vez na história, com a criação das lojas de departamentos, os consumidores começaram a sentir-se como massa (antigamente, só a escassez lhes dava esta sensação). Com isso aumenta consideravelmente o elemento circense e teatral do comércio". 5

Os anacronismos do "templo do consumo" criado por Zola no romance (luz elétrica, projeto arquitetônico da loja, e mesmo a derrocada do pequeno comércio) já foram bastante comentados. Mas, além disso, chamam a atenção os fundamentos modernos que iriam sustentar o aperfeiçoamento daquele tipo de comércio capitalista. Opondo-se ao pessimismo dos homens cultivados e blasés que iriam compor a fisionomia finissecular, o empreendedor Octave Mouret, proprietário do magazine, defende com entusiasmo as carreiras que se abriam aos homens práticos, "quando o século inteiro se lança para o futuro", e se alia ele próprio ao capital bancário, por sua vez aliado do poder público que administra a cidade, todos comungando nos interesses do capital. ${ }^{6}$

Uma questão decisiva depende também de uma perspectiva crítica de problemas que se mostrarão duradouros, e se referem às crescentes e abissais diferenças, que são de classe social, entre as chances de exercer o que se considera "vontade livre" dos sujeitos - conceito do qual se abusa muito, mas que não é medida de nenhum fenômeno. A esse respeito, o leitor poderá encontrar, em outros romances de Zola, mais material para uma reflexão sobre a pretensa liberdade da vontade, no limite impossível, a exemplo de Germinal, de 1885. O desfecho de Germinal faz pensar que a "vontade livre" não é a mesma para os operários da mina de carvão e para o futuro jornalista Étienne Lantier. ${ }^{\top}$

$\mathrm{O}$ assunto está também em Au bonheur des dames. O comércio de novidades é tributário de concepções de tempo de trabalho plasmadas pela indústria como experiência propriamente moderna e promissora. Mas será possível ir além de uma tese sobre a humanização da atividade comercial como "o embrião das grandes sociedades trabalhadoras do século vinte" (como se lê no romance), afirmação sempre destacada pela crítica para marcar um juízo do próprio romance sobre o moderno sistema comercial? Se for possível ir além, isso se deve ao modo como Zola expõe, na própria forma do romance, os resultados do alcance do mundo das mercadorias.

\footnotetext{
5 "Característica específica das lojas de departamentos: os compradores sentem-se como massa; são confrontados aos estoques; abrangem todos os andares com um só olhar; pagam preços fixos; podem "trocar as mercadorias'" (ver Walter Benjamin, Passagens, org. Willi Bolle, Belo Horizonte, Editora UFMG; São Paulo, Imprensa Oficial do Estado, 2006, p. 80, 86, 98).

${ }^{6}$ Traduzi todas as citações do texto original do romance.

${ }^{7}$ É como leio o final de Germinal, quando Étienne Lantier parte para Paris, depois de acabado seu período de "educação" na mina de carvão, indo assumir o papel que lhe está reservado como "ideólogo da revolução" ("raisonneur"). Ele acredita numa revolução próxima, sente ódio da burguesia, mas também já se sente incomodado com o "cheiro da miséria". Retomando seu caminho pessoal, Étienne sonha colocar os trabalhadores na glória, e já se vê "na tribuna triunfando com o povo, se o povo não o devorasse".
} 
Pressionada entre um senso de degradação da vida (e os limites de um modelo de prosa) e as ideologias do progresso (que nem sempre as intenções pessoais do artista foram capazes de superar, como confirmam os romances posteriores ao ciclo dos Rougon-Macquart), a forma narrativa revela contradições que são, ao mesmo tempo, da matéria e de sua apreensão ficcional. E através da inserção de um material melodramático (ou de uma intriga romanesca) numa prosa de teor épico, sem chegar a ironizar explicitamente a intriga, o romance realista de Zola deixa implícita uma reflexão sobre os desafios formais que iriam se impor às narrativas do novo tempo que se abria.

Se essa questão for deslocada para uma ordem não ficcional, esses desafios, que são os das condições históricas objetivas incrustados nas formas narrativas disponíveis, ficarão reduzidos à formulação de apreciações sobre o próprio escritor, ora visto como socialista crítico, ora como liberal otimista, ora como positivista agnóstico (como prefere Lukács). Donde a necessidade de entender o sentido que assume o melodrama que, se usado na sua função canônica, simplesmente traria para o âmbito individual e apolítico o que deveria ser procurado no âmbito das relações sociais, reatando com uma tradição romântica que anula contradições e escolhe a via da fantasia como consolação para as crueldades do mundo. No entanto, não é isso o que acontece em $\mathrm{Au}$ bonheur des dames.

Embora o romance seja considerado o primeiro em que Zola dá destaque aos mecanismos capitalistas, observados nos procedimentos dos grandes magazines parisienses, a crítica também tem afirmado que Zola teria visto, no "monstro irresistível", uma saída depois da crise econômica de 1882. "Tudo somado, é possível dizer que Zola, com Au Bonheur des dames, cauciona a utopia e a ilusão dos filantropos de seu tempo", escreve Jeanne Gaillard, num sentido bastante discutível de utopia, que leva em conta a oposição do escritor à reação moralista que, nos anos de 1880, acusava o consumo de luxo de dissolver a moral e os bons costumes (as manifestações alcançavam também a construção do metrô) ${ }^{8}$

Num estudo recente, o romance é um "relatório darwiniano" das convulsões psicológicas e comportamentais causadas pelo êxito desse tipo de comércio, que provoca tragédia e vítimas com suas condições de trabalho e seu regime de concorrência brutal, mas também apaixona com o espetáculo das mercadorias e a emoção do consumo. Retomando a interpretação corrente do caráter fabular do enredo - o casamento entre desiguais, a moça pobre (Denise) e o rapaz rico (Mouret), Rachel Bowlby detém-se na construção da figura de Denise, que concilia o modelo da "moça maternal" ao da empresária moderna, bem sucedida ao criar melhores condições de trabalho e triunfando sobre a onipotência masculina.

\footnotetext{
${ }^{8}$ Ver Jeanne Gaillard, "Prefácio", in Emile Zola, Au bonheur des dames, Ed. anotada e estabelecida por Henri Mitterand, Paris, Gallimard, 1980. Ao endossar a tese de que Zola estaria defendendo "utopias do seu tempo", Jeanne Gaillard lembra que iniciativas como seguros para períodos de inatividades no trabalho, bibliotecas, cursos de música e de línguas para os empregados tinham sido criadas entre 1872 e 1876 no "Bon Marché", a loja de departamentos parisiense, por sugestão da mulher do proprietário.
} 
Na condição feminina caberia também cinismo, já que ela é cúmplice da especulação de mulheres e crianças (quando chefe da seção infantil). A interpretação de Bowlby considera que Denise "jamais se imaginou como potencial cliente", e por isso salva "a família, reinventando-a como fundamento ético de uma instituição capitalista de vastas dimensões", ao conseguir transformar "a impiedosa lógica econômica". Cito o parágrafo final de Bowlby: "Transformados pelo amor de uma boa mulher, tanto o homem quanto o grande magazine avançam para um século $\mathrm{XX}$ que confirmará as intuições antecipatórias de Denise, mãe-gerente de um grande empreendimento econômico atento ao bem-estar social". ${ }^{9}$

Em resumo, de acordo com as duas interpretações o romance dá soluções, ainda que de alcance diversos. Na primeira delas, ratificando uma ideologia do seu tempo; na segunda, apreendendo uma totalidade problemática ao prenunciar uma ideologia futura que, no entanto, não parece levar às últimas consequências (por isso mesmo não cabe à interpretação crítica mais do que reconhecer a premonição). Seja conformando-se ao otimismo acrítico e individualizante das promessas liberais (Gaillard chega a sugerir que Zola não faz diferença entre aburguesamento e socialismo), seja antecipando a manipulação moderna do princípio ético, as duas interpretações levam a pensar na posição paralisante de uma prosa que não incorporaria nenhum ponto de transformação, e manteria a dicotomia entre sistema e indivíduo.

Numa outra direção, sugiro que o lado mais instigante do romance, tanto ficcional quanto político, formaliza uma critica e uma reflexão dupla sobre a matéria e o modo de tratá-la, através da montagem de registros narrativos diversos, sendo que o ponto de transformação é dado pelo próprio desequilíbrio entre eles. Se estivermos interessados em observar o que diz a forma de um romance que faz mais do que transformar o magazine de monstro em benfeitor, sem se esborrachar na prioridade do romanesco, veremos que a coexistência dos dois registros narrativos é que problematiza a complexidade da matéria. Uma coexistência tensa e sem solução à vista. Privilegiar a ação dramática, como via de regra se faz, significa conferir à narrativa um teor regressivo e ingênuo.

No entanto, a forma de um romance só pode fazer pensar pela própria régua e compasso que oferece. Nesse sentido, não se deve perder de vista que a prosa de Zola inclui, programaticamente, a esfera privada no horizonte público. O registro épico mostra o reino das promessas constitutivo das próprias mercadorias, por meio do qual o consumo dá aparência de liberdade à sujeição dos homens ("em seguida foram as lãs escocesas, em diagonal, em relevo, todas as variedades de lã, que ela teve a curiosidade de tocar, só por prazer, já decidida no íntimo a levar qualquer uma"). O procedimento da descrição é aqui a chave para a montagem das cenas narrativas.

O processo de reificação é diretamente proporcional à presença assustadoramente humana dos objetos e das mercadorias. As imagens concretas e palpáveis,

${ }^{9}$ Ver Rachel Bowlby, "O desejo: o paraíso das damas", in A cultura do romance, org. Franco Moretti, trad. Denise Bottmann, São Paulo, CosacNaify, 2009. 
tais como se apresentam aos clientes, sustentam a montagem de cenas que submergem numa temporalidade lenta, priorizando relações erráticas de todos com todos em torno das mercadorias e do consumo, e conferindo um peso aos acontecimentos que já não é o previsto numa narrativa centrada na narração como sequências necessárias ditadas pela linha geral da ação. ${ }^{10}$

As relações entre personagens não são apreensíveis por leis psicológicas e sociológicas (como Zola também esclarecia como parte do seu programa), mas acompanham o movimento do cálculo mercantil do qual dependem os acontecimentos descritos e narrados, tendo como eixo central os espetáculos que se sucedem: a massa de clientes ("era um novo espetáculo, um oceano de cabeças vistas em atalhos, escondendo os bustos, fervilhando numa agitação de formigueiro"), as mulheres "pálidas de desejo" e "mãos glutonas" diante das sedas, "pobres mulheres sem defesa" diante da renovação dos estoques esteticamente expostos em arranjos vivos de cores e tatos.

Em certo momento, o vestíbulo transformado num magnífico salão oriental, com o luxo de tapetes raros, será isca para consumidores de arte ("A Turquia, a Pérsia e a Índia estavam ali"). E no triunfo final, com as demolições que abrem espaço para mais um "templo construído para a loucura consumista da moda", a luta será entre os grandes. O banqueiro financia dois magazines, e um deles tem a bela ideia de levar o pároco da Madeleine para benzer a loja (Mouret pensa então em recorrer ao arcebispo). Afinal, é a "a religião do banco" que invade magnificamente todas as seções, e as descrições apreendem a própria alma da vida pública de Paris ("o rio humano nadava sob a alma desfraldada de Paris, um grande e doce sopro, onde se sentia uma enorme carícia").

Nesse registro o leitor é levado a questionar o argumento conservador do fatalismo abundantemente empregado por Octave Mouret e por Denise, como justificativa da sua ardente defesa do empreendimento comercial a cuja lógica econômica eles são servis. Se assim for, Zola inverte os próprios termos de um romance e de uma recepção aferradas às aparências e coniventes com os termos de uma felicidade privada mercantilizada, que, afinal, bloqueia todo movimento genuíno de insatisfação e inconformismo social.

Mas esse fatalismo encontra resistência entre os pequenos comerciantes massacrados que lutarão até que suas forças se esgotem, sem compactuar. Neles, a obsessão pelo grande magazine é de outra natureza, enquanto a identidade de Denise é forjada, desde o início da narrativa, nas suas relações com o magazine e a partir do seu desenraizamento da própria classe social, a favor do capital, alegorizado pelas relações com a família do tio Baudu e com os outros comerciantes que, prestes a serem dizimados, ainda a acolhem fraternalmente em momentos de necessidade.

${ }^{10}$ A análise de Antonio Candido do romance L'Assommoir (1877) leva em conta o sentido dessa inversão para a exposição do estado psíquico e dos comportamentos das personagens, onde os elementos que poderiam parecer acessórios na narrativa, constituídos pela descrição, são, na verdade, mediações decisivas para o caráter simbólico dos espaços do bairro operário (ver Antonio Candido, "Degradação do espaço", in O discurso e a cidade, São Paulo, Livraria Duas Cidades, 1993). 
Apesar da extensa documentação histórica de que sempre se valia Zola, o massacre dos pequenos proprietários é anacronismo com função estrutural, e não se limita a opor passado e presente para tomar partido do progresso que tem Denise como heroína e musa.

O outro registro, incrustado no primeiro (e que pode ser visto como excrescência, ou como resíduo de uma forma anterior), é o do andamento melodramático, que destaca uma jovem pobre, sofredora e bondosa, mas também destemida, com senso das oportunidades e tino comercial-amoroso profundamente ético. Tensionado pela contiguidade com o registro épico, ele não sustenta o enredo de final feliz como solução das contradições da matéria e da forma. Ainda que essa coexistência possa parecer uma má resolução, qualquer objeção desse tipo será revertida se atentarmos para o sentido do conjunto, uma estranha e esgarçada totalidade.

O melodrama narra a aceitação subserviente do fatalismo destrutivo do progresso que o romance não escamoteia, dando a ver Denise engolida "pela lógica dos fatos", apesar dos horrores que presencia ("Há muito tempo ela mesma estava presa nas engrenagens da máquina. Pois ela não tinha sangrado?). Ao escolher Mouret, depois de viver a tragédia coletiva, lemos:

A força que varria tudo, a carregava junto, a ela, cuja presença deveria ser revanche. Mouret tinha inventado esta máquina de massacrar o mundo, cujo funcionamento brutal a indignava; ele tinha semeado ruínas no bairro, despojado uns, matado outros; e ela o amava justamente pela grandeza de sua obra, ela o amava ainda mais a cada um dos excessos do seu poder, apesar do rio de lágrimas que a excitava, diante da miséria sagrada dos vencidos.

A contradição entre os registros é a figura seminal da prosa, que dá a ver o cerne da experiência moderna nas próprias artimanhas narrativas que se valem da ideia do ímpeto progressista da natureza humana. Desse modo, qualquer aposta autoral perde todo o interesse diante da força da prosa que revela os bastidores de uma negação que, ilusoriamente, acredita encontrar satisfação justamente ali onde a sua própria experiência subjetiva já não pode existir, como é o caso exemplar de Denise, retalhada entre a paixão pelo andamento dos negócios e a experiência cruel do seu caráter predatório, demolidor e mortal em relação à sua própria classe social, sem deixar de optar pelo primeiro: essa a "mãe-gerente" a que se refere Rachel Bowlby.

A descrição das mercadorias e das atividades implicadas no comércio moderno torna-se, portanto, ela mesma, a linha narrativa principal e o móvel das emoções, sentimentos e relações intersubjetivas. A alegoria que o romance monta, contando com o viés melodramático como uma antinarrativa, apanha as figuras do proprietário, empregados, clientes, pequenos comerciantes, investidores financeiros e fornecedores enquanto tipos constitutivos de um processo, o mercantil, localizados em lugares diferentes no sistema de produção e consumo, e sem os quais seria impossível sua sistematização ficcional.

Não é pouca coisa observar que, num romance realista escrito nos anos de 1880, apenas o registro melodramático possa satisfazer ao desejo de um final feliz. A paixão, se é que a narrativa trata disso, será impossível sem o comércio e o lucro 
("aquela força que transformava Paris"), que o registro épico impiedosamente desmonta ao narrar o triunfo das mercadorias ("a seção das sedas era como um quarto de amor, drapeado em branco por um capricho de uma apaixonada nua como a neve, desejando combater em brancura").

É sempre o magazine, motor em plena marcha, que agarra e congrega imaginações e tem o poder de dar sentido a existências sem dignidade e a mortes que revelam a vilania ("A senhora Baudu manteve os olhos fixos, cheios da visão do monumento triunfante, daqueles vidros límpidos, atrás dos quais passava um galope de milhões [...] e quando eles se apagaram na morte, continuaram ainda abertos, olhando sempre, embaçados por espessas lágrimas").

Como em outros romances do ciclo, as referências a encenações teatrais exigem posição ativa do espectador-leitor: em vez da unidade tradicional e da dramatização de pontos de vista individuais, o que se tem é o desmascaramento de um espetáculo de falseamento ideológico, com uma multidão de atores. As atitudes de comando direto e eficiente de Octave Mouret alegorizam a ideologia do trabalho que rege o novo comércio, costurada por poses de "patrão humano" e pela encenação de relações pessoais que ratificam a gratidão dos empregados, que dependem do interesse do capital para "satisfazer as paixões" ("Mouret entrou em cena para fazer o papel de bom príncipe", ele "que adorava lances teatrais"). ${ }^{11}$

Duas referências ao falanstério tratam de distanciá-lo da utopia de Charles Fourier - sociedades coletivas brotando de um ímpeto natural, que seriam anônimas e com divisão de lucros - e de atrelá-lo aos mecanismos de mercado, insistindo na contradição como figura-chave da narrativa: a aposta piedosamente otimista do registro romanesco, cuja realização depende de agentes individuais, aposta também nas condições da sua impossibilidade. Antes das conquistas de Denise, o falanstério é máquina infernal que engole a todos ("Todos não eram mais do que engrenagens, eram levados pela máquina, abdicando de sua personalidade, adicionando simplesmente suas forças, ao todo banal e poderoso do falanstério. Apenas lá fora, a vida individual reaparecia, com a brusca chama das paixões que acordavam").

E quando alimentado pelo sonho de "melhorar o mecanismo" comercial, de criar uma "cidade do trabalho" onde cada um "teria sua parte exata dos benefícios, segundo seus méritos, com a certeza do amanhã assegurada por um contrato", o que dará à máquina poder ainda maior, quase divino, o falanstério depende de "argumentos tirados do próprio interesse dos patrões" e virá como expiação pelas desgraças e mortes, para as quais Denise encontra explicações, ingênuas ou cínicas, no confronto com o registro épico da tragédia coletiva ("Sim, era a parte do sangue, toda revolução fazia seus mártires, só se marchava em frente sobre os mortos").

$\mathrm{Na}$ verdade, trata-se de sair do mesmo para voltar ao mesmo: esse o diagnóstico da prosa. Como dirá uma cliente sobre o magazine, ele "é um mundo [...] Não se sabe mais onde se está". Um mundo em constante movimento, onde a certa

11 Um outro exemplo de referência teatral trabalhada de modo diverso, mas também com sentido crítico, é a pontuação irônica e caricata das encenações que são do agrado da burguesia de Passy, que nelas procuram um ideal de autenticidade e sinceridade, em Une page d'amour (1878). 
altura já nada se distingue de nada, nem pessoas nem mercadorias, todas despedaçadas num festival comum de partes de uma engrenagem. Nas vendas de inverno ou de verão, nas exposições das novidades da estação, ou na inauguração de novas lojas que entronizam definitivamente o poder das estruturas de ferro, "a Indústria e o Comércio se dão as mãos" e a clientela se diversifica, "todos febris pela mesma paixão" que lhes traz a extrema e eterna felicidade do consumo, além de refrescos e salas de leitura. Mais tarde serão concertos executados por um grupo de empregados e divulgados junto ao público.

Destaco o comentário descritivo do narrador sobre a lógica que desperta "novos desejos" e novas necessidades na própria carne das mulheres, numa "democratização do luxo" que, a rigor, é movimento frenético e cotidiano que alimenta a ilusão de luxo para todos e, sobretudo, alimenta o capital ("o capital sempre renovado"). Talvez seja possível transcrever, entre tantos, um trecho que configura o objeto da narrativa, passando pela animada descrição de procedimentos comerciais (fornecedores, estoques, números, organização dos departamentos, promoções, premiações que levam os empregados a mergulhar "apaixonadamente no trabalho" procurando erros nas notas de débitos).

No ar imóvel, onde a sufocação do aquecedor amornava o cheiro dos tecidos, o burburinho aumentava, feito de todos os barulhos, dos passos contínuos, das mesmas frases cem vezes repetidas em volta dos balcões, da moeda sonante sobre o couro das caixas assentadas numa desordem de porta-níqueis, de cestos rolantes onde as cargas dos pacotes caíam sem cessar em grandes porões. E, sob a poeira fina, tudo acabava por se confundir, não se reconhecia mais a seção das sedas; abaixo, a seção de aviamentos parecia inundada; mais distante, nos tecidos de algodão branco, um raio de sol, vindo da vitrine da rua Neuve-Saint-Augustin, parecia uma flecha de ouro na neve; aqui, na seção de luvas e lãs, uma massa espessa de chapéus e arranjos de cabelo bloqueava os fundos da loja. Não se viam nem mesmo os vestidos, apenas os penteados flutuavam, entulhados de plumas e fitas; alguns chapéus de homens eram manchas negras, enquanto a tez pálida das mulheres, de fadiga e calor, tinha a transparência de camélia. ${ }^{12}$

Como apanhar o sentido mais fundo e perturbador da sensação de segurança das pessoas por pagar preços fixos pelas mercadorias, da sensação de liberdade por poder trocá-las depois de compradas, da sensação de domínio e poder ao abarcar com um só olhar todos os andares da loja, além de ter contato direto com grandes estoques? Como narrar as promessas das mercadorias de integrar e satisfazer a todos para sempre? Como conciliar tudo isso com uma aposta no novo comércio - "uma nova religião", onde o proprietário reinava "com a brutalidade de um déspota" - tido como fator de progresso e de conquista de direitos?

12 "O realismo ao qual aspiram também idealistas, não é primário, mas derivado: o realismo por perda da realidade. Uma literatura épica que não controla mais as relações de objeto que ela procura apanhar e fixar é obrigada a exagerá-la pela sua atitude de descrever o mundo com uma precisão excessiva, precisamente porque ele tornou-se estranho, porque não se pode mais tocá-lo com o dedo. Esta nova objetividade que, mais tarde, será levada à dissolução do tempo e da ação, uma conseqüência muito moderna em obras como Le Ventre de Paris, de Zola, já contém no procedimento de Stifter e mesmo nas formulações do velho Goethe, um núcleo patogênico, o eufemismo" (ver Adorno, "Lectures de Balzac", op. cit., p. 92). 
A decisão de Mouret pelo casamento ("a santidade necessária") se mescla à euforia por haver alcançado o lucro de um milhão num único dia. Denise vê o dinheiro na escrivaninha. Enquanto ela ainda negaceia, "aquele milhão imbecil" os espreita ("inútil"), mas é sobre ele que Mouret se senta enlaçando Denise que, afinal, consente. Os anti-heróis Denise e Mouret são atravessados pela mercantilização generalizada, que apanha um Mouret antes de tudo lógico na consecução dos interesses financeiros e amorosos ("Então ele lhe tomou as mãos, disse numa explosão de ternura, depois da indiferença que havia se imposto: - E se eu a esposasse, Denise, você partiria?"). Seus suspiros pela inutilidade da fortuna diante das negativas de Denise compõem um tipo que só tem sentido na prosperidade dos negócios (para a qual Denise contribui).

Contrariando a lógica mercantil que rege as ditas relações de afeto, que dá segurança e atende aos interesses de um e de outro, é o tio Baudu quem, espoliado dos próprios afetos e trabalho e vivendo num sanatório, tinha sido capaz de comentar o que a narrativa expõe ao incorporar um enredo melodramático à encenação épica realista. Numa ocasião em que, mais uma vez, Denise lhe tinha exposto suas ideias sobre as "necessidades dos tempos modernos", a inevitabilidade do progresso, "a grandeza das novas criações, enfim o bem-estar crescente do público", ele dissera: "Tudo isso, são fantasmagorias". E completando seu juízo: "Não há sentimento no comércio, há apenas cifras". Au bonheur des dames é um desafio às novas configurações da interdependência inevitável entre relações subjetivas e sociais. ${ }^{13}$

${ }^{13}$ Sobre a fantasmagoria das mercadorias, Walter Benjamin fala em "atualidade eternizada", retomando a ideia de fetichismo em Marx, a saber, a ocultação e, por isso mesmo, a eternização do processo de exploração do homem através da transformação do produto do seu trabalho em mercadorias cambiáveis entre si. 